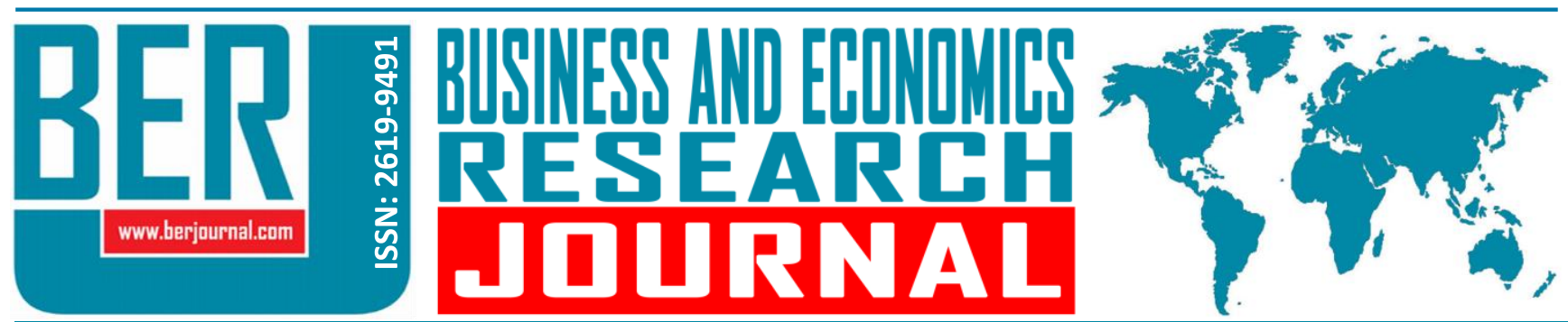

Business and Economics Research Journal Vol. 10, No. 3 Special Issue, 2019, pp. 687-698 doi: 10.20409/berj.2019.193

\section{Sermaye Yapısının Belirlenmesinde Finansman Hiyerarşisi Teorisi: Türkiye'deki İşletmeler Üzerine Panel Veri Analizi*}

\author{
Sefika Nilay Onatca Engin ${ }^{\mathrm{a}}$, Cansu Unver Erbas ${ }^{\mathrm{b}}$, Ahmet Gokhan Sokmen
}

Öz: Sermaye yapısı kararları, işletmelerin faaliyetlerini devam ettirebilmeleri ve sağıklı bir biçimde büyüyebilmeleri açısından üzerinde durulması gereken önemli bir konudur. Bu çalışmanın amacı işletmelerin sermaye yapısı belirleyicilerini tespit etmek ve gerçek hayatta işletmelerin hangi sermaye yapısı teorisine uygun davranış sergilediklerini ortaya koymaktır. Sermaye yapısını belirleyici unsurların özelliklerini ve bu unsurların sermaye yapısını ne yönde etkilediklerini bilmek sermaye yapısı kararlarının daha etkin bir şekilde alınmasını sağlayacaktır. Bu amaç doğrultusunda, hisseleri Borsa istanbul'da işlem gören 186 imalat sanayi işletmesinin 2009-2016 yılları arasındaki bilanço ve gelir tablosu verilerinden yararlanılarak panel veri analizi yapılmıştır. Analiz sonuçları söz konusu işletmelerin finansman hiyerarşisi teorisine uygun davrandıklarını fon kaynağı ihtiyacında öncelikli olarak iç fon kaynaklarını tercih ettiklerini, iç fon kaynaklarının yetersiz olması durumunda dış fon kaynaklarını kullanma yoluna gittiklerini göstermiştir.

\section{Pecking Order Theory in Determining The Capital Structure: A Panel Data Analysis Of Companies in Turkey}

\begin{abstract}
Capital structure decisions are an important issue that should be emphasized in order to enable enterprises to continue their activities and grow in a healthy manner. The purpose of this study is determining the capital structure and evaluating which capital structure theory fits the firms' attitude. Knowing the characteristics of the determinants of capital structure and how they affect the capital structure will enable capital structure decisions to be taken more effectively. For this purpose, panel data analysis was carried out by using the balance sheets and income statements data of 186 manufacturing companies, whose shares are traded in istanbul Stock Exchange between the years 2009-2016. The results of the analysis indicate that firms firstly use internal funds. External funds are used only when internal funds are insufficient. The results of the analysis show that these firms' attitudes are fit with the pecking order theory.
\end{abstract}

Anahtar Sözcükler: Sermaye Yapısı, Finansman Hiyerarşisi Teorisi, Hedef Borçlanma Oranı, Panel Veri Analizi, İmalat Sanayi İşletmeleri

JEL: C23, G32

$\begin{array}{ll}\text { Geliş } & : 05 \text { Şubat } 2019 \\ \text { Düzeltme } & : 12 \text { Mart } 2019 \\ \text { Kabul } & : 22 \text { Mart } 2019 \\ & \\ \text { Tür } & : \text { Araştırma }\end{array}$

Keywords: Capital structure, Pecking Order Theory, Target Debt Ratio, Panel Data Analysis, Manufacturing Companies

JEL: C23, G32

$\begin{array}{ll}\text { Received } & : 05 \text { February } 2019 \\ \text { Revised } & : 12 \text { March } 2019 \\ \text { Accepted } & : 22 \text { March } 2019 \\ \text { Type } & : \text { Research }\end{array}$

\footnotetext{
a Res. Asst., Cag University, Faculty of Economics and Administrative Sciences, Mersin Turkiye, sefikanilayonatca@cag.edu.tr (ORCID ID: 0000-0002-0891-8743)

b Asst. Prof., PhD., Loughborough University, Leicestershire, UK, c.unver-erbas@lbora (ORCID ID: 0000-0002-8905-5037)

c Asst. Prof., PhD., Cag University, Faculty of Economics and Administrative Sciences, Mersin Turkiye, gokhansokmen@cag.edu.tr (ORCID ID: 0000-0002-1836-8378)
} 


\section{Giriş}

İşletmeler kurulabilmeleri ve faaliyetlerini sürdürebilmeleri için sermayeye ihtiyaç duyarlar. İşletmelerin sermaye yapısı borç ve özsermaye olmak üzere iki başlık altında toplanabilir. İşletmelerin sermaye yapılarını oluştururken ne oranda borç ne oranda özsermaye kullanmaları gerektiği finans literatürünün en tartışmalı konularından biridir. Bu tartışmaların genel odağı işletmelerin sermaye yapılarında değişiklik yaparak optimal sermaye yapısına ulaşılıp ulaşılamayacağı ve işletmelerin sermaye yapısında yapılacak değişikliğin ortalama sermaye maliyetine ve işletme değerine etkisi üzerine olmuştur. Finans literatüründe sermaye yapısı kararı alma ve optimal sermaye yapısına ulaşmaya ilişkin pek çok yaklaşım ve teori ortaya koyulmuştur. Bu çerçevede net gelir yaklaşımı, net faaliyet geliri yaklaşımı, geleneksel yaklaşım ve Modigliani Miller (MM) yaklaşımı klasik sermaye yapısı teorilerini oluşturmaktadır. Net gelir yaklaşımı, işletme değerinin belirlenmesi açısından kaldıraç oranını en aşırı biçimde dikkate alan yaklaşımdır. Kaldıraç oranı ne kadar yüksek olursa işletme değeri de bu oranla doğru orantılı olarak artacaktır (Akgüç, 2013: 485). Yüksek kaldıraç oranının işletme değerini arttırmasıyla optimal sermaye yapısına erişilecektir. Net faaliyet geliri yaklaşımı, sermaye yapısı içerisindeki borç düzeyinin artmasının özsermaye maliyetini yükselteceğini, ancak ağırlıklı ortalama sermaye maliyetini ve işletme değerini değiştirmeyeceğini varsayar (Ercan ve Ban, 2014: 231) Geleneksel yaklaşım, işletmelerin tek bir optimal sermaye yapısı olduğunu öne sürer ve işletmelerin finansal kaldıracı yükselterek işletmenin sermaye maliyetini düşürebileceğini ve işletme değerini yükseltebileceğini savunur (Horne ve Wachowicz, 2008: 449). MM yaklaşımı ise işletmenin finansal kaldıraç derecesi ile işletmenin sermaye maliyeti arasındaki ilişkiyi ne faaliyet geliri yaklaşımı ile aynı şekilde açıklar (Horne ve Wachowicz, 2008: 456). Bu yaklaşıma göre finansal kaldıracın derecesi her ne olursa olsun işletmenin sermaye maliyetini etkilemediği savunulur (Akgüç, 2013: 497). Daha sonra finansal sıkıntı ve iflas maliyeti, temsil maliyeti, asimetrik bilgi gibi piyasa aksaklıklarının da dikkate alınmasıyla gerçek hayatta sermaye yapısı davranışlarını açıklamada daha elverişli olduğu düşünülen dengeleme teorisi ve finansman hiyerarşisi teorisi olmak üzere iki modern teori geliştirilmiş̧ir. Dengeleme teorisi, işletmenin sermaye yapısı kararlarının borcun vergi tasarrufu avantajı ile borçtan kaynaklanan finansal sıkıntı maliyeti arasındaki dengelemeyi içerdiğini savunmaktadır (Brealey vd., 2007: 425). İ̧letmeler borçlandıklarında optimal noktaya kadar borcun vergi tasarrufundan faydalanmakta ve işletme değeri yükselmektedir. Optimal noktadan sonra eğer işletme borçlanmayı sürdürürse finansal sıkıntı ve iflas riski artar, borcun vergi tasarrufu ortadan kalkar (Damodaran, 2001: 550). Bu durum işletmelerin neden devamlı borçlanamayacaklarını açıklamaktadır. Finansman hiyerarşisi teorisine göre ise işletmeler, finansman sağlamada öncelikli olarak asimetrik bilgi problemi içermeyen iç fon kaynaklarını (oto finansman) kullanmayı tercih ederler. iç fon kaynakları tükendikten sonra dış kaynakları (borç) kullanırlar. En son olarak da özsermaye finansmanı yaparlar. Dolayısıyla bu kuram, dengeleme teorisinin açıklayamadığı en karlı işletmelerin daha az borçlanması durumunu açıklamaktadır. Bu işletmeler, karlılık oranları yüksek olduğu için dış kaynağa gereksinim duymamaktadırlar (Arnold, 2005: 985).

Bu çalışmanın amacı hisseleri BiST'te işlem gören imalat sanayi işletmelerinin sermaye yapısı belirleyicilerinin neler olduğunu ve bu belirleyicilerin sermaye yapısı kararlarına ne yönde etki ettiklerinin tespit etmek ve literatürde yer alan finansman hiyerarşisi teorisinin geçerliliğini analiz etmektir. Uygulamada BIST imalat sanayi endeksinde, 2009-2016 yılları arasında faaliyet gösteren 186 işletme incelenmiştir. Literatürden faydalanılarak bağımlı ve bağımsız değişkenler seçilmiştir. Seçilen değişkenlere bağlı kalınarak model oluşturulmuş ve Stata 14 programı yardımıyla panel veri analizi uygulanmıştır. Daha sonra analiz sonucunun tutarlılığını ölçmek ve daha fazla değişkenin sermaye yapısı üzerindeki etkisini gösterebilmek amacıyla modele farklı değişkenler eklenip çıkarılarak analizler yapılmıştır.

\section{Literatür Taraması}

Sermaye yapısı, finans literatüründe en çok tartışılan ve üzerinde çok çeşitli araştırmalar yapılan en önemli konulardan bir tanesidir. Bu çalışmalarda işletmelerin borçlanma kararlarını etkileyen faktörler saptanmaya çalışılmış ve sermaye yapısı teorilerinin işletmelerin sermaye yapılarını açıklama yetenekleri incelenmiştir. Bu bölümde, işletmelerin sermaye yapısı belirleyicilerine ilişkin Dünya'da ve Türkiye'de yapılmış çalışmalar hakkında özet bilgilere yer verilmiştir. 
Sermaye yapısına dair ilk çalışma, Modigliani ve Miller tarafından 1958 yılında yapılmıştır. Bu çalışmada 43 elektrik işletmesinin 1947-1948 yıllarını kapsayan verileri ve 42 petrol işletmesinin 1953 yılına ait verileri kullanılmıştır. Çalışmada iflas riskinin, vergilerin, asimetrik bilgi ve temsil maliyetleri gibi piyasanın neden olduğu maliyetlerin olmaması durumunda işletmenin sermaye maliyeti ve piyasa değeri ile sermaye yapısı arasında bir ilişki bulunmadığı sonucuna ulaşımıştır.

Modigliani ve Miller, ilk çalışmalarından beş yıl sonra vergi değişenini de göz önünde bulundurarak yeni bir makale kaleme almışlardır. 63 elektrik işletmesinin 1954-1957 yılları arasındaki verilerini kullanarak yaptıkları çalışmalarında işletmelerin borç kullandıklarında borcun vergi avantajından faydalanarak piyasa değerini yükseltebileceklerini vurgulamışlardır. Ancak bu borçlanmanın devamlı olmayacağını, bir noktadan sonra borçlanma maliyetinin özkaynak maliyetini aşabileceğini de vurgulamışlardır.

Literatürde işletmelerin sermaye yapısı davranışlarında finansman hiyerarşisi teorisini takip ettiklerini gösteren çok sayıda çalışma vardır. Özer ve Yamak (2000), 1996 yılı itibarı ile İstanbul'da faaliyet gösteren 101 küçük ve orta ölçekli konaklama işletmesinde işletmelerin sahip ya da yöneticileri ile yüz yüze görüşme ve anket yöntemi ile veri topladıkları çalışmalarında işletmelerin finansmanda öncelikle iç kaynakları tercih ettiklerini göstermişlerdir. Aynı şekilde Kula (2000), 1999 yılında Afyon Organize sanayi Bölgesi'nde ve Ankara yolunda faaliyetini sürdüren küçük ve orta ölçekli 80 firma ile yüz yüze görüşme ve anket yöntemi ile gerçekleştirdiği çalışmasında işletmelerin piyasadaki genel ekonomik iktidarsızlıktan etkilenerek borçlanmadan kaçındıklarını göstermiştir ve enflasyon ve faiz oranlarının yüksek olmasının işletmelerde borçlanmaya olan eğilimi azalttığı sonucuna varmıştır. Fıratoğlu (2005) , 1992-2000 yılları arasında iMKB'de işlem gören 196 mali olmayan firmayı dahil ettiği panel veri analizi çalışmasında işletmeleri piyasa aksaklıklarının var olduğu durumda incelemiştir. Analiz sonuçlarına göre, işletmelerin kriz dönemlerinde de finansmanda öncelikle iç kaynaklara yöneldiklerini saptamıştır. Akyüz ve diğerleri (2006), 1999-2001 yılları arasında Karadeniz bölgesindeki mikro, küçük ve orta ölçekli 850 firmaya uyguladığı anket çalışmalarında işletmelerin finansmanda öncelikle iç kaynakları tercih ettiklerini gösterirken, Yılgör ve Yücel (2007) de Adana Sanayi Odası ile Mersin Ticaret ve Sanayi Odasına kayıtlı olan ve ankete yanıt veren 382 firma ile yaptıkları çalışmalarında işletmelerin hedef borç oranlarının olmadığını borçla finansmanda ölçülü davrandıklarını tespit etmişlerdir bu sonuçlar söz konusu işletmelerin finansman hiyerarşi teorisini takip ettiklerini göstermektedir, Erkan ve Aydemir (2006) ise, Türkiye'deki 38 ilde faaliyet gösteren 438 firmada anket çalışması yapmışlar ve yine finansman hiyerarşisi teorisini destekler nitelikte işletmelerin finansmanda öncelikle iç kaynakları tercih ettiği sonucuna ulaşmışlardır.

\section{Veri Seti ve Değişkenler}

Çalışmada, Borsa İstanbul'da işlem gören imalat sanayide faaliyet gösteren 186 işletmenin 2009-2016 dönemlerini kapsayan yıllık verileri ele alınarak bir panel veri seti oluşturulmuştur. Analizlerde bağımlı değişken olarak finans literatüründe finansal kaldıraç oranı olarak yaygın bir biçimde kullanılan Toplam Borç /Toplam Varlık oranı kullanılmıştır. Sermaye yapısının belirleyici faktörleri ise bağımsız değişkenler olarak tanımlanmıştır. Bu değişkenler firmaya özgü faktörlerden seçilen likidite, borç dışı vergi kalkanı, varlık yapısı, net çalışma sermayesi, büyüme oranı gibi değişkenlerdir. Ayrıca bu bağımsız değişkenlere ek olarak modele makro bir değişken olan vergi oranı da eklenerek kaldıraç üzerindeki etkileri tekrar test edilmiştir.

Tablo 1. Değişkenler İçin Kullanılan Oranlar

\begin{tabular}{|c|c|c|}
\hline \multicolumn{2}{|c|}{ Değişken } & Kullanılan Oran \\
\hline \multicolumn{2}{|c|}{ Finansal Kaldıraç } & Toplam Borç /Toplam Varlık \\
\hline \multirow{2}{*}{ Likidite } & Cari Rasyo & Dönen Varlıklar / Kısa Vadeli Borç \\
\hline & Net Çalışma Sermayesi & (Dönen Varlıklar-Kısa Vadeli Borçlar) / Dönen Varlıklar \\
\hline \multicolumn{2}{|c|}{ Borç Dışı Vergi Kalkanı } & Amortisman / Toplam Varlıklar \\
\hline \multicolumn{2}{|c|}{ Varlık Yapısı } & Duran Varlıklar / Toplam Varlıklar \\
\hline \multicolumn{2}{|c|}{ Büyüme Oranı } & Varlıklardaki bir önceki döneme göre değişim \\
\hline \multicolumn{2}{|c|}{ Karlılık (Aktif Karlılığı) } & Net kar/ Toplam Varlıklar \\
\hline \multicolumn{2}{|c|}{ Vergi Oranı } & Ödenecek Vergi/ Vergi Öncesi Kar \\
\hline
\end{tabular}




\section{Bağımsız Değişken 1: Likidite}

Sermaye yapısı konusunda yapılan çalışmalar genellikle likidite oranı ile borç kullanımı arasındaki ilişkiyi negatif olarak kabul etmektedir. Finansal hiyerarşi teorisine göre, işletmeler finansman sağlamada öncelikli olarak iç kaynaklarını kullanmayı tercih ederler. Bu nedenle likit kaynakları fazla olan işletmeler dışardan bir finansman kaynağına gereksinim duymazlar. (Kaur ve Roa, 2009: 102) Diğer bir deyişle, likidite gücü yüksek olan işletmeler yatırım ve faaliyet giderlerini kendi fonlarıyla karşılayabildiği için daha az borçlanma yoluna gitmektedir. Likidite oranı ile kaldıraç oranı arasındaki ilişkinin finansal hiyerarşi teorisine uyumlu olarak negatif yönlü olduğunu destekleyen çok sayıda çalışma vardır: Özkan (2001); Mallikarjunappa ve Goveas (2007); Şen ve Oruç (2008); Ata ve Ağ (2010); Sheikh ve Wang (2011); Ansari ve Bideskan (2012); Abdioğlu ve Deniz (2015); Kara ve Erdur (2015).

\section{Bağımsız Değişken 2: Karlıık}

Finansman hiyerarşisi teorisi, işletmeler yatırımlarında öncelikle iç kaynaklardan finansman yoluna gittikleri için karlı işletmelerin daha az borçlandığını öne sürer. İşletmeler ancak yatırımlarının bedelinin karlarını aştığı durumda borç kullanma yoluna giderler (Myers, 1984). Dolayısıyla finansman hiyerarşisi teorisinde, kaldıraç ve karlıı̆ın ters bir ilişki içerisinde olması gerektiği ifade edilmiştir. Karlııı ile kaldıraç arasında negatif yönlü bir ilişki olduğunu destekleyen çalışmalar: Chiarella ve diğ.(1992); Özkan (2001); Pandey (2001); Huang (2006); Booth vd. (2001); Chen ve Strange (2005); Büyüktortop (2007); Shah ve Khan (2007); Şen ve Oruç (2008); Teker ve diğerleri (2009); Terim ve Kayalı (2009); Yıldız ve diğerleri (2009); Akinlo (2011); Yakar (2011); Ansari ve Bideskan (2012); Thippayana (2014); Correia (2015); Vergas, Cerqueira ve Brandão (2015). Literatürdeki çalışmaların oldukça büyük bir kısmı karlılık ve kaldıraç arasındaki ilişkide finansal hiyerarşi teorisinin fazlaca kabul gördüğünü göstermektedir.

\section{Bağımsız Değişken 3: Büyüme Oranı}

İşletmelerde büyümenin kaldıraç oranlarını nasıl etkilediği ile ilgili literatürde farklı görüşler bulunmaktadır. Bir kııım görüş, büyümekte olan işletmelerin temsil maliyetlerini düşürebilmek için daha az borç kullanmayı tercih edebileceklerini öngörürken diğer bir kısım işletmenin büyümesi ile birlikte güven sağlayacağı ve borçlanma yeteneğini artırabileceğini savunmaktadır.

Bu görüşlerden ilkini destekleyen Galai ve Masulis (1976), Jensen ve Meckling (1976) ve Myers (1977), büyüme oranı yüksek olan işletmelerin temsil maliyetlerini düşürebilmek için daha az borç kullanmayı tercih edebileceklerini savunmaktadır. Aynı doğrultuda Baskin (1989), yüksek büyümenin, büyük iflas riski yaratacağını savunmaktadır. Kreditörler hızlı büyüyen fakat riskli olan işletmelere kredi sağlamayı istemeyeceklerinden dolayı bu işletmelerin borçlanma oranları daha düşük olacaktır (Cortez ve Susanto, 2012). Bu da dengeleme teoreminin kabulleri ile tutarlıdır. Gaud vd. (2005); Shah ve Khan (2007); Akinlo (2011); Gülşen ve Ülkütaş (2012) çalışmalarında büyüme oranı ile kaldıraç arasındaki ilişkinin negatif olduğunu destekleyen sonuçlara ulaşmışlardır.

Bu görüşün karşıtı ise finansman hiyerarşisi teorisidir. Bu teori işletmelerin büyüme oranı ile kaldıraç kullanımları arasındaki ilişkinin pozitif olduğunu kabul eder. Gupta (1969), işletmelerin büyümesiyle doğru orantılı olarak gelecekteki borçlanma yeteneklerinin artacağını böylece işletmenin varlıklarını finanse edebilmek için borç kullanmaya yöneleceklerini savunmuştur. Aynı şekilde, hızı büyüyen işletmeler yavaş büyüyen işletmelere göre daha fazla yatırım fırsatına sahip olurlar (Myers, 1977: 148). Daha fazla yatırım yapan bu işletmeler karlarında tutarlılık sağlayabilecek ve bu sayede daha rahat borçlanabileceklerdir. Manos ve Ah-nen (2003); Voulgaris, Asteriou ve Agiomirgianakis (2004); Sayılgan ve diğerleri (2006); Yakar (2011); Shah ve Kausar (2012); Abdioğlu ve Deniz (2015) çalışmalarında büyüme oranı ile kaldıraç arasında pozitif ilişki olduğu sonucuna ulaşmışlardır.

\section{Bağımsız Değişken 4: Borç Dışı Vergi Kalkanı}

Amortisman, yatırım kredileri ve yatırım teşvik indirimleri gibi vergi tasarrufu sağlayan kalemler borç dışı vergi kalkanı olarak tanımlanmaktadır. Borç dışı vergi kalkanları, borçla finansmandan sağlanan vergi avantajının ikamesi olarak kullanılabilmektedir (Wiwattanakantang, 1999: 385). De Angelo ve Masulis (1980) 
bu sayede daha fazla borç dışı vergi kalkanına sahip olan işletmelerin daha düşük oranda borç kullanımına yöneleceklerini öne sürmüştür. Ayrıca işletmenin borç dışı vergi kalkanı düzeyinin yüksek olması borcun muhtemel vergi avantajını azaltıcı etki yapmakta dolayısıyla kaldıraç oranı ile borçlanma arasında negatif yönlü bir ilişkiye sebep olmaktadır (Deesomsak ve diğerleri, 2004: 394). Hem finansman hiyerarşisi teorisi hem de dengeleme teorisine uyumlu olarak borç dışı vergi kalkanı düzeyi ile kaldıraç oranı arasında negatif bir ilişki olduğunu destekleyen çalışmalar vardır: Upneja ve Dalbor (2001); Özkan (2001); Fama ve French (2002); Bauer (2004); Huang (2006); Büyüktortop, (2007); Teker ve diğerleri (2009); Terim ve Kayalı (2009); Uysal (2010); Sayılgan ve Uysal (2011).

Temsilcilik teorisine göre ise yatırım indiriminden yüksek oranda faydalanma ve borçlanma arasındaki ilişkinin pozitif yönlü olması öngörülür. Bunun nedeni işletmenin yatırım indiriminden fazla yararlanması ve amortisman giderlerinin fazla olmasının o işletmenin teminat gösterebileceği maddi duran varlıklarının fazla olduğu anlamına gelmesidir. Bu da işletmeyi kaldıraç kullanımına daha eğimli hale getirecektir. (Bradley ve diğerleri, 1984: 874) Temsilcilik teorisi ile uyumlu olarak borç dışı vergi kalkanı düzeyi ile kaldıraç oranı arasında pozitif bir ilişki olduğunu destekleyen çalışmalar: Titman ve Wessel (1988); Mallikarjunappa ve Goveas (2007); Tortop (2007); Awan ve Amin (2014); Abdioğlu ve Deniz (2015).

\section{Bağımsız Değişken 5: Vergi Oranı}

Borçlanmanın sermaye yapısı üzerindeki en belirgin etkisi işletmelerin borçları karşılı̆̆ında ödeyecekleri faiz giderlerinin vergi matrahından düşülerek vergi kalkanı oluşturabilmeleridir (Harris ve Raviv, 1990: 321-349). Böylece yüksek vergi oranına sahip olan işletmeler vergi kalkanından daha fazla faydalanacaklardır. Bu durum vergi oranı ile kaldıraç oranı arasında pozitif yönlü bir ilişkiye işaret eder.

İşletmeler, gereksinim duydukları kaynağın finansmanında en basit haliyle özkaynak ya da yabancı kaynak kullanmayı seçmek durumundadırlar. Bu seçimde, en önemli etken kaynağın işletmeye olan maliyetidir. Modigliani ve Miller 1958 yılında yayınladıkları çalışmalarına kurumlar vergisini de ilave ederek 1963 yılında bir düzeltme yayınlamışlardır. Bu çalışmalarında işletmelerin borçlanma yolunu seçerek elde ettikleri vergi avantajına değinmişlerdir. Ardından Miller (1977), Taggart (1980), Pozdena (1987), Titman ve Wessels (1988) tarafından ileri sürülen görüşler de borçlanmanın vergi avantajı var iken, kar payı ödemelerinin böyle bir avantajı olmadığını destekler niteliktedir. Huang ve Song (2004) ve Tortop (2007) da vergi oranının kaldıracı pozitif etkilediğini tespit etmiştir.

Çalışmada kullanılan bağımlı ve bağımsız değişkenler ve bu değişkenlerin analizlerde kullanılan simgeleri Tablo 2'de gösterilmiştir:

Tablo 2. Çalışmada Kullanılan Bağımlı ve Bağımsız Değişkenler

\begin{tabular}{|l|l|}
\hline Bağımlı değişken & Analizlerde Kullanılan Simgesi \\
\hline Finansal Kaldıraç & kald 1 \\
\hline Bağımsız değişkenler & Analizlerde Kullanılan Simgesi \\
\hline Cari Rasyo & $c r$ \\
\hline Borç Dışı Vergi Kalkanı & $b d v k$ \\
\hline Varlık yapısı & $d v o$ \\
\hline Net Çalışma Sermayesi & $n c ̧ s$ \\
\hline Büyüme Oranı & $b o 1$ \\
\hline Karııık & $k a r$ \\
\hline Vergi Oranı & vergi \\
\hline
\end{tabular}

\section{Metodoloji}

Araştırmanın veri setine dahil olan, imalat sanayide faaliyet gösteren 186 işletmenin 2009-2016 dönemlerini kapsayan yıllık verileri ile panel veri analizi gerçekleştirilmiştir. Panel veri analizi örneklem setine 
ait ülkeler, işletmeler, hane halkları gibi kesit gözlemlerinin belirli bir zaman diliminde bir arada incelenmesi olarak tanımlanabilir (Baltagi vd., 2005: 1). 2009-2016 yılları arasındaki ilişki tek bir işletme için incelendiğinde zaman serisi analizi, 2009 yılı için farklı işletmelerin sermaye yapısı belirleyicileri incelendiğinde ise yatay kesit analizi yapılmış olmaktadır. Bu çalışmada, zaman serisi analizi ve yatay kesit analizini bir araya getiren panel veri analizi yönteminin kullanılması uygun görülmüştür.

Kullanımı gittikçe yaygınlaşan panel veri analizinin avantajlarından bazıları şu şekilde sıralanabilir (Cameron ve Trivedi, 2005: 697; Baltagi vd., 2005: 4-7; Pazarlığlu ve Gürler, 2007: 37; Gujarati, 2003: 637; Hsiao, 2014: 4-9):

- Panel veri analizinde hem zaman hem de yatay kesitten veri geldiği için daha fazla veri kullanma şansı vardır. Bu sayede zaman serisi veya yatay kesit analizlerini tek başlarına açıklayamadıkları daha karmaşık davranış modellerinin kurulmasına ve test edilmesine olanak verir.

- Yatay kesit verileri ile zaman serisi verilerinin birleştirilmesiyle ortaya çıkan panel veriler daha çok doğrusal bağlantı, daha fazla serbestlik derecesi ve daha fazla etkinlik sağlamaktadır.

- Panel veri modellerindeki gözlem sayısının zaman ve kesit serilerine göre daha çok olması parametre tahminlerinin de daha güvenilir olmasını sağlamaktadır.

- Veri sayılarının artmasıyla birlikte çoklu doğrusallık sorunu azalacak ve böylece iktisadi tahminlerin güvenirliği de artmaktadır.

- Yatay kesit verisi kullanılarak yapılan tahminlerde, sadece birimler arasındaki farklılıklar incelenebilirken, panel veri kullanılarak hem birimler hem de bir birim içerisinde meydana gelen farklılıklar birlikte incelenebilmektedir.

Panel veri ile yapılan regresyonlarda en sık kullanılan iki yöntem sabit etkiler modeli ve tesadüfi (rassal) etkiler yöntemidir. Bu çalışmada, değişkenlerin sermaye yapısını nasıl belirlediklerini ortaya çıkarmak amacıyla birer model oluşturabilmek için Jerry Hausman (1978) tarafından öne sürülen Hausman testinden yararlanılarak uygun panel veri modelleri belirlenmiştir (Wooldrige, 2002: 288). Hausman testi, çalışmada Sabit Etkili ve Rassal Etkili Modellerden hangisinin tercih edilmesi gerektiğine karar verebilmek için kullanılan bir testtir. (Greene, 2002: 301). Yapılan Hausman test istatistiklerine göre olasılık değeri 0.05' ten küçük çıkmıştır (Prob>chi2=0,00<0,05). Bu durum çalışmada sabit etkiler modelinin baz alınmasının uygun olacağını göstermektedir. Ayrıca, yapılan LM testinde $t$ istatistik oldukça anlamlı sonuç vermiş̧ir ve kurulan 'model sabit etkiler modelini destekliyor' boş hipotezi reddedilmiştir. Sonuçlar Hausman test ile uyumlu olarak sabit etkiler modelinin kullanılması gerektiğini doğrulamaktadır. Model seçiminin ardından, sabit etkiler modelinde değişen varyans ve otokorelasyon testleri yapılmıştır. Sabit etkiler modelinde birimlere göre değişen varyans sorunu olup olmadığının belirlenmesi amacıyla Breusch-Pagan/ Cook-Weisberg testi uygulanmıştır. Test sonuçları modelde birimlere göre değişen varyans problemi olduğunu göstermiştir. Bu durum çalışma için bir kısıt olup gelecek çalışmada modellemenin GMM ile yapılması bu problemi ortadan kaldırabilir. Otokorelasyon test sonuçlarına bakıldığında ise özellikle finansal kaldıraç bağımlı değişkeni ile cari rasyo bağımsız değişkeni arasında güçlü ve ters yönlü bir ilişki olduğu göze çarpmaktadır.

Analizde kullanılacak başlıca regresyon modelleri aşağıdaki gibidir:

Model 1: $\quad \log _{-} k a l d 1_{i t}=\beta_{0_{i}}+\beta_{1} \log _{-} c r_{i t}+\beta_{2} b d v k_{i t}+\beta_{3} \log _{-} d v o_{i t}+\beta_{4} \log _{-} n c ̧ s_{i t}+\beta_{5} b o 1_{i t}+\varepsilon_{i t}$

Model 2: $\log _{-} k_{a l d 1_{i t}}=\beta_{0 i}+\beta_{1} k a r_{i t}+\beta_{2} \log c r_{i t}+\beta_{3} b d v k_{i t}+\beta_{4} \log _{-} d v o_{i t}+\beta_{5} \log _{-} n c ̧ s_{i t}+\beta_{6} v e r g i_{i t}+\varepsilon_{i}$

Burada,

$\beta_{0}$ : sabit değeri; $\beta_{1}, \beta_{2}, \beta_{3}, \beta_{4}, \beta_{5}, \beta_{6}$ : tahminlenecek katsayıları; $\varepsilon_{i}$ :hata değerini; $i$ :firma grubunu; $t$ :zamanı ifade etmektedir. 
Çalışmanın tutarılıı̆ını ölçmek ve güvenirliliğini artırabilmek bu sayede literatürdeki, çalışmalarla kıyaslama yapabilmek amacıyla en makul şekilde bağımsız değişken kullanmaya özen gösterilmiştir. Bu doğrultuda çalışmaya ikinci bir model eklenerek literatürde yaygın olarak kullanılan karlılık değişkeninin de kaldıraç kullanımına etkisi gözlenmek istenmiştir, aynı zamanda diğer bağımsız değişkenlerin de kaldıraç üzerindeki etkisi tespit edilerek sonuçlar arasındaki tutarlılı̆a bakılmıştır. Model 1'de kullanılan değişkenler işletmeye özgü belirleyicilerden oluşmaktadır. Model 2'de makro bir değişken olan verginin durumu nasıl etkilediği de gözlenmek istenmiş bu doğrultuda analize vergi değişkeni de eklenerek tekrar test edilmiştir.

\section{Ampirik Bulgular}

TB/TV finansal kaldıraç oranının regresyon sonuçları Tablo 3'te verilmiştir. Analiz sonuçlarına göre $R^{2}$ değeri 0,7902 çıkmıştır. Bu veri çalışmada kullanılan model ve veri seti arasındaki uyumun yüksek olduğunu göstermektedir. Sosyal bilimler alanı için bu oran modelin oldukça anlamlı olduğunu işaret etmektedir. Yapılan Hausman Test ve LM test sonuçları, çalışmada sabit etkiler modelinin baz alınması gerektiğini göstermişti. Ancak sonuçlarımızdaki tutarlılı̆ı da değerlendirebilmek amacıyla FE (sabit etkiler modeli) ile birlikte OLS (en küçük kareler yöntemi), RE (rassal etkiler modeli), TFE (zamansal sabit etkiler modeli) sonuçları da beraberinde gösterilmiştir.

Tablo 3. Model 1 İçin Regresyon Sonuçları

\begin{tabular}{r|cccc}
\hline Değişken & OLS & RE & FE & TFE \\
\hline log_cr & $-.7622261^{* * *}$ & $-.55894546^{* * *}$ & $-.43558657^{* * *}$ & $-.41893242^{* * *}$ \\
bdvk & .77970832 & .32743227 & .90391111 & .7914528 \\
log_dvo & $-.41122922^{* * *}$ & $-.23074788^{* * *}$ & $-.13066867^{* * *}$ & $-.1213152^{* *}$ \\
log_nçs & $-.05207926^{* * *}$ & $-.10013953^{* * *}$ & $-.1867125^{* * *}$ & $-.20980622^{* * *}$ \\
bo1 & $.19759581^{* * *}$ & $.09091254 *$ & .07404432 & .05851009 \\
_cons & $-1.8257541^{* * *}$ & $-2.6140409^{* * *}$ & $-4.1612202^{* * *}$ & $-4.5684368^{* * *}$ \\
\hline r2_a & .79023681 & & .66321828 & .66614308 \\
$\mathrm{~N}$ & 1250 & 1250 & 1250 & 1250 \\
$\mathrm{~F}$ & 41.515 .271 & & 64.855461 & 45.060262 \\
\hline$* \mathrm{p}<.1 ;{ }^{* *} \mathrm{p}<.05 ; * * * p<.01$ & & &
\end{tabular}

Tablo 3' te verilen bağımlı değişkeni finansal kaldıraç oranı olan regresyon analiz sonuçları sabit etkiler modeline göre incelendiğinde $\mathrm{cr}$, nçş değişkenlerinin \%1 anlamlılık düzeyinde ilişkili olduğu görülmektedir. dvo değişkeninin olasılık değeri ise $\% 5$ düzeyinde anlamlı olarak bulunmuştur. cr sembolü ile temsil edilen cari rasyo değişkeni \%1 anlamlılık düzeyinde -0,4355 katsayı ile finansal kaldıraç oranını en güçlü düzeyde açıklayan bağımsız değişkendir.

Yapılan regresyon analizi sonucunda, finansal kaldıraç oranı ile net çalışma sermayesi ve cari rasyo arasında anlamlı negatif bir ilişki olduğu görülmektedir. Net çalışma sermayesi ve cari rasyo değişkenleri işletmenin likiditesini ölçmektedir. Bu değişkenlerin her ikisinin de kaldıraç oranına etkisinin anlamlı ve aynı yönlü olması sonuçların tutarlılı̆ını göstermektedir. Aynı zamanda sonuçlar OLS, RE, TFE model sonuçlarında da aynı yönlü ve istatistiksel olarak önemli derecede anlamlı bulunmuştur. Literatürdeki çalışmalara bakıldığında, sermaye yapısı konusunda yapılan çalışmaların genellikle likidite oranı ile borç kullanımı arasındaki ilişkiyi negatif kabul ettiği gözlenmişti. Bu ilişkinin negatif yönlü olması likidite gücü yüksek olan işletmelerin yatırım ve faaliyet giderlerini kendi fonlarıyla karşılayabildikleri için daha az borçlanma yoluna gitmelerinden kaynaklandığı düşünülmektedir. Bu durum finansman hiyerarşisi teorisini destekler niteliktedir.

'dvo' bağımsız değişkeni ile finansal kaldıraç bağımlı değişkeni arasında sabit etkiler modeli sonucuna göre negatif ve $-0,13$ katsayısı ile $\% 5$ düzeyinde anlamlı bir ilişki bulunmuştur. OLS, RE, TFE modellerinin sonuçlarına bakıldığında da aynı şekilde negatif ve anlamlı sonuçlara ulaşıldığı görülmektedir. Bu negatif ilişkinin nedeni, varlık yapısında daha fazla duran varlığa sahip olan işletmelerin finansal risklerinin düşük 
olması ve bu işletmelerin daha fazla güvenceye sahip olmaları bu sayede daha az borç kullanmaları olduğu düşünülmektedir. Bu sonuçlar da finansman hiyerarşisi teorisini desteklemektedir.

'bo1'bağımız değişkeni ile finansal kaldıraç oranı arasında bütün panel veri modellerinde tutarlı olarak pozitif bir ilişki görülmektedir. Bu sonucun büyüme oranı yüksek olan işletmelerin daha fazla yatırım fırsatına sahip olmasından kaynaklandığı düşünülmektedir. Bu sonuç da finansman hiyerarşisi teorisini destekler niteliktedir.

Tablo 4. Model 2 İçin Regresyon Sonuçları

\begin{tabular}{r|cccc}
\hline \multicolumn{1}{c|}{ Değişken } & OLS & $\mathrm{RE}$ & $\mathrm{FE}$ & $\mathrm{TFE}$ \\
\hline kar & -.01770921 & -.04582162 & -.03347831 & -.03391905 \\
log_cr & $-.77170672 * * *$ & $-.59878874^{* * *}$ & $-.51878768^{* * *}$ & $-.51018099 * * *$ \\
bdvk & .15500766 & -.25841068 & .07616194 & .03322298 \\
log_dvo & $-.43167251^{* * *}$ & $-.26799348^{* * *}$ & $-.18416115^{* * *}$ & $-.17857489^{* * *}$ \\
log_nçs & $-.04982045^{* * *}$ & $-.09031416^{* * *}$ & $-.14343096^{* * *}$ & $-.15660071^{* * *}$ \\
vergi & .00257155 & $.00190593^{* *}$ & $.00161378^{*}$ & $.00157639^{*}$ \\
cons & $-1.754101^{* * *}$ & $-2.4175145^{* * *}$ & $-3.3471664 * * *$ & $-3.5782571^{* * *}$ \\
\hline $\mathrm{r}$ _a & .79597668 & & .66533342 & .66711937 \\
$\mathrm{~N}$ & 1433 & 1433 & 1433 & 1433 \\
$\mathrm{~F}$ & 398.87843 & & 55.354011 & 36.253123 \\
\hline$* \mathrm{p}<.1 ; * * \mathrm{p}<.05 ; * * * p<.01$ & & &
\end{tabular}

Analizde kullanılan değişkenler işletmeye özgü belirleyicilerden oluşmaktadır. Makro bir değişken olan vergi oranının durumu nasıl etkilediği gözlemlenmek istenmiş bu doğrultuda analize Tablo 4' de görüldüğü gibi 'vergi' değişkeni eklenerek tekrar test edilmiştir. Sonuçlar, önceki analiz sonuçlarıyla tutarlı kalmıştır.

Analiz sonuçlarına bakıldığında, önceki modellere benzer şekilde $R^{2}$ değeri 0,7959 olarak bulunmuştur. İşletme likiditesini ölçen 'cr' ve 'nçs' değişkenlerinin ve varlık yapısını gösteren dvo değişkeninin finansal kaldıraç oranı üzerindeki negatif ve istatistiksel olarak anlamlı etkisi bütün panel veri modelleri için aynı kalmıştır. Aynı şekilde cr $1 \%$ anlamlıık düzeyinde -0,5187 katsayı ile finansal kaldıraç oranını en güçlü düzeyde açıklayan bağımsız değişken olarak kalmıştır. Ayrıca bdvk değişkeni de aynı şekilde pozitif ve istatistiksel olarak anlamsız sonuç vermiştir. Bu durum çalışmanın tutarııı̆ıın göstermekte ve güvenirliliğini artırmaktadır.

Literatürdeki çalışmaların büyük bir çoğunluğu vergi değişeni ile kaldıraç oranı arasında pozitif bir ilişkiye işaret etmiştir. Bu çalışmanın sonuçları da literatür ile uyumlu olarak vergi değişkeni ile finansal kaldıraç oranı arasındaki ilişkiyi FE panel veri modeli sonuçlarına göre istatistiksel olarak anlamlı ve pozitif olduğunu göstermiştir. OLS, RE, TFE modelleri de bu sonuçlara tutarlılık göstermektedir. Ancak 0016 katsayısı beklentimizin altında kalmıştır. Pozitif ilişki beklentimizin nedeni borç karşılığı ödenen faiz giderinin vergi matrahından düşülebilmesidir. Böylece işletmeler bu vergi avantajından daha fazla yararlanabilmek için daha fazla borçlanma yoluna gideceklerdir.

Literatürdeki çalışmaların büyük bir kısmı karlılık ve finansal kaldıraç arasında negatif bir ilişki tespit etmiştir. Bu çalışmada da Tablo 3'te analize eklenen 'kar' bağımsız değişkeninin finansal kaldıraç üzerindeki etkisine baktığımızda literatürü destekler nitelikte bütün panel veri modelleri için karlıık ve finansal kaldıraç arasında negatif bir ilişki olduğu gözlenmiştir. Bunun nedeninin işletmelerin yatırımlarında öncelikle iç kaynaklardan finansmanı tercih etmesi, dolayısıyla karlılığın artmasının borçlanmayı azaltıcı etki yapması olduğu düşünülmektedir. Bu durum yine finansman hiyerarşisi teorisini destekler niteliktedir.

\section{Sonuç}

Sermaye yapısı kararları, işletmelerin faaliyetlerini devam ettirebilmeleri ve sağlıklı bir biçimde büyüyebilmeleri açısından üzerinde durulması gereken önemli bir konudur. Son yıllarda ekonomi, teknoloji 
gibi alanlarda yaşanan gelişmeler, işletmelerin elde edebilecekleri fon kaynaklarının çeşitlenmesini sağlamış, finansal işlemleri daha az maliyetle ve uluslararası düzeyde gerçekleştirebilmeyi kolaylaştırmıştır. Günümüzde rekabetin hızla artıyor olması fon kaynakları arasında doğru seçim yapabilmeyi ve bu seçimin işletmeye ne kadar maliyet getireceği konusuna dikkat edilmesini gerektirmektedir.

Sermaye yapısını belirleyici unsurların özelliklerini, sermaye yapısını ne yönde etkilediklerini bilmek sermaye yapısı kararlarının daha sağlıklı bir şekilde alınmasını sağlayacaktır. Sermaye yapısı kararı almada işletmeler iç ve dış çevrelerinden etkilenirler. Ancak hangi faktörden ne kadar etkilendikleri konusunda bir fikir birliği bulunmamaktadır. Bu çalışmada işletmeye özgü faktörler ve ülkenin genel ekonomik durumu göz önüne alınarak işletmenin sermaye yapısı belirleyicilerinin neler olduğu ve bu belirleyicilerin sermaye yapısına nasıl bir etki yaptıkları tespit edilmeye çalışımıştır.

Finans literatüründe sermaye yapısı kararı alma ve optimal sermaye yapısına ulaşmaya ilişkin pek çok yaklaşım ve teori ortaya koyulmuştur. Bu çerçevede net gelir yaklaşımı, net faaliyet geliri yaklaşımı, geleneksel yaklaşım ve MM yaklaşımı bulunmaktadır. Daha sonra finansal sıkıntı ve iflas maliyeti, temsil maliyeti, asimetrik bilgi gibi piyasa aksaklıklarının da dikkate alınmasıyla gerçek hayatta sermaye yapısı davranışlarını açıklamada daha elverişli olduğu düşünülen dengeleme teorisi ve finansman hiyerarşisi teorisi olmak üzere iki yeni teori geliştirilmiştir. Dengeleme teorisi, optimal sermaye yapısına borçlanmanın getirdiği fayda ve maliyetlerin dengelenmesiyle ulaşılabileceğini öne sürerken, finansman hiyerarşisi teorisi işletmelerin sermaye yapılarını oluştururken ilk olarak işletmenin iç kaynaklarını tercih edeceğini, iç kaynakların yetersiz olması durumunda borçlanma ile finansman sağlayacaklarını ve son olarak da pay senedi ihraç etme yoluna gideceklerini savunmaktadır. Ancak hangi teorinin sermaye yapısı kararlarını tam olarak açıklayabildiği konusunda ortak bir sonuca ulaşılamamıştır.

Bu çalışmada, sermaye yapısının belirleyici faktörlerinin uygulamada nasıl şekillendiğini açıklamak ve işletmelerin sergiledikleri sermaye yapısı davranışlarının hangi teoriyle uyumlu olduğunu ortaya koymak amacıyla Borsa İstanbul'da işlem gören tüm imalat sanayi işletmelerinin bilanço ve gelir tablolarından yararlanılarak panel veri analizi yapılmıştır. Elde edilen bulgular Borsa İstanbul'da işlem gören imalat sanayi işletmelerinin büyük ölçüde finansman hiyerarşisi teorisine uygun olarak davrandığını göstermektedir.

Çalışma sonuçlarına göre likidite gücü yüksek olan işletmeler daha az borç kullanmaktadır, bu da işletmelerin yatırımlarını öncelikle iç kaynaklardan finanse ettiğini göstermektedir. Varlık yapısında daha fazla duran varlığa sahip olan işletmelerin daha düşük kaldıraç oranına sahip oldukları gözlenmiştir bunun nedeninin finansal risklerinin düşük olması sebebiyle daha az maliyetle hisse arz edebildiklerinden kaynaklandığı düşünülmektedir. İşletmelerin büyümesi ile doğru orantılı olarak gelecekteki borçlanma yeteneklerinin arttığı ve varlıklarını finanse edebilmek için borçlanmaya yöneldikleri düşünülmektedir. Ödenen vergi oranı yüksek olan işletmelerin daha fazla finansal kaldıraçtan yararlandığı gözlenmiştir. Bu pozitif ilişkinin nedeninin ise borç karşılığı ödenen faiz giderinin vergi matrahından düşülebilmesi olduğu düşünülmektedir. Böylece işletmeler bu vergi avantajından daha fazla yararlanabilmek için daha fazla borçlanma yoluna gideceklerdir. Tüm bu bulgular örneklemi oluşturan işletmeleri finansman hiyerarşisi teorisine yaklaştırmaktadır.

Bu çalışma sadece BiST' te işlem gören imalat sanayi işletmeleri üzerine yapılmıştır. Bundan sonraki yapılacak çalışmalarda gelişmekte olan diğer ülkelerde faaliyet gösteren imalat sanayi işletmeleri de incelenerek kıyaslamalar yapılabilir.

\section{Son Notlar}

* Bu çalışma, 28-29-30 Kasım 2018 tarihlerinde düzenlenen "IV. International Conference on Applied Economics and Finance \& Extended with Social Sciences (ICOAEF'18)" kongresinde sözlü olarak sunulmuş ve öz kısmı Bildiri Özetleri Kitabında yayınlanmıştır. 


\section{Kaynaklar}

Abdioğlu, N., \& Deniz, D. (2015). Borsa İstanbul'da işlem gören imalat sanayi şirketlerinin sermaye yapılarının firmaya özgü belirleyicileri. Sosyoekonomi, 23(26), 195-213.

Akgüç, Ö. (2013). Finansal yönetim (9. Baskı). İstanbul: Avcıol Basım.

Ahmed Sheikh, N., \& Wang, Z. (2011). Determinants of capital structure: An empirical study of firms in manufacturing industry of Pakistan. Managerial Finance, 37(2), 117-133.

Akinlo, O. (2011). Determinants of capital structure: Evidence from Nigerian panel data. African Economic and Business Review, 9(1), 1-16.

Akyüz, K. C., Akyüz, I., Serin, H., \& Cindik, H. (2006). The financing preferences and capital structure of micro, small and medium sized firm owners in forest products industry in Turkey. Forest policy and Economics, 8(3), 301-311.

Ansari, A., \& Bideskan, M. S. S. (2012). Determinants of capital structure. Society for Business Research Promotion, 2(2), 51-63.

Arnold, G. (2005). Corporate financial management (3rd Edition). Prentice-Hall.

Ata, H. A., \& Ăg, A. G. Y. (2010). Firma karakteristiğinin sermaye yapısı üzerindeki etkisinin analizi. Ekonometri ve istatistik e-Dergisi, (11), 45-60.

Awan, A., \& Amin, M. S. (2014). Determinants of capital structure. European Journal of Accounting Auditing and Finance Research, 2(9), 22-41.

Baltagi, B. H., Bratberg, E., \& Holmås, T. H. (2005). A panel data study of physicians' labor supply: The case of Norway. Health Economics, 14(10), 1035-1045.

Baskin, J. (1989). An empirical investigation of the pecking order hypothesis. Financial Management, 18, 26-35.

Bauer, P. (2004). Determinants of capital structure: empirical evidence from the Czech Republic. Czech Journal of Economics and Finance (Finance a uver), 54(1-2), 2-21.

Booth, L., Aivazian, V., Demirguc-Kunt, A., \& Maksimovic, V. (2001). Capital structures in developing countries. The journal of finance, 56(1), 87-130.

Bradley, M., Jarrell, G. A., \& Kim, E. (1984). On the existence of an optimal capital structure: Theory and evidence. The Journal of Finance, 39(3), 857-878.

Brealey, R. A., Myers, S.C., \& Macus, A. J. (2007). İşletme finansının temelleri. Çev. Ü. Bozkurt, T. Arıkan, \& H. Doğukanlı. İstanbul: McGraw-Hill ve Literatür Ortak Yayını.

Büyüktortop, M. (2007). Çokuluslu işletmelerde sermaye yapısı ve iMKB'de bir uygulama. Gazi Üniversitesi Sosyal Bilimler Enstitüsü, Yüksek Lisans Tezi, Ankara.

Cameron, A. C., \& Trivedi, P. K. (2005). Microeconometrics: Methods and applications. Cambridge University Press.

Chen, J., \& Strange, R. (2005). The determinants of capital structure: Evidence from Chinese listed companies. Economic Change and Restructuring, 38(1), 11-35.

Chiarella, C., Pham, T. M., Sim, A. B., \& Tan, M. (1992). Determinants of corporate capital structure: Australian evidence. Pacific Basin Capital Markets Research, 3, 139-158.

Correia, A. M. F. A., Cerqueira, A. M., \& Brandao, E. (2015). Determinants of corporate capital structure: Evidence from non-financial listed French firms. FEP Working Papers.

Cortez, M. A., \& Susanto, S. (2012). The determinants of corporate capital structure: evidence from Japanese manufacturing companies. Journal of International Business Research, 11(3), 121.

Damodaran, A. (2001). Corporate finance theory and practice (2nd Ed.). Wiley International Edition.

DeAngelo, H., \& Masulis, R. W. (1980). Optimal capital structure under corporate and personal taxation. Journal of Financial Economics, 8(1), 3-29.

Deesomsak, R., Paudyal, K., \& Pescetto, G. (2004). The determinants of capital structure: Evidence from the Asia Pacific region. Journal of Multinational Financial Management, 14(4), 387-405.

Ercan, M. K., \& Ban, Ü. (2014). Değere dayalı işletme finansı- finansal yönetim (8. Baskı). Ankara: Gazi Kitabevi.

Erkan, M., \& Aydemir, O. (2006). İşletmelerin finansman kararları ve yabancı kaynak kullanımı: Türkiye'de bir uygulama. Marmara Üniversitesi Muhasebe-Finansman Araştırma ve Uygulama Dergisi: Analiz, 6(15), 131-139. 
Fama, E. F., \& French, K. R. (2002). Testing trade-off and pecking order predictions about dividends and debt. Review of Financial Studies, 15(1), 1-33.

Fıratoğlu, B. (2005). Şirketlerin sermaye yapısını etkileyen faktörler ve kriz dönemlerinde şirket davranışlarında meydana gelen değişiklikler. Sermaye Piyasası Kurulu Araştırma Raporu, Ankara.

Galai, D., \& Masulis, R. W. (1976). The option pricing model and the risk factor of stock. Journal of Financial economics, 3(1-2), 53-81.

Gaud, P., Jani, E., Hoesli, M., \& Bender, A. (2005). The capital structure of Swiss companies: An empirical analysis using dynamic panel data. European Financial Management, 11(1), 51-69.

Greene, W. H. (2002). Econometric analysis (5th Ed.). New Jersey: Prentice Hall.

Gujarati. D. (2003). Basic econometrics (4th Ed.). McGraw-Hill.

Gupta, M. C. (1969). The effect of size, growth, and industry on the financial structure of manufacturing companies. The Journal of Finance, 24(3), 517-529.

Gülşen, A. Z., \& Ülkütaş, Ö. (2012). Sermaye yapısının belirlenmesinde finansman hiyerarşisi teorisi ve ödünleşme teorisi: IMKB sanayi endeksinde yer alan firmalar üzerine bir uygulama. Uluslararası Yönetim iktisat ve işletme Dergisi, 8(15), 49-59.

Harris, M., \& Raviv, A. (1990). Capital structure and the informational role of debt. The Journal of Finance, 45(2), 321349

Hausman, J. A. (1978). Specification tests in econometrics. Econometrica, 46(6), 1251-1271.

Horne, J. C. V., \& Wachowicz, J. M. (2008). Fundamentals of financial management (13th Ed.).

Hsiao, C. (2014). Analysis of panel data (No. 54). Cambridge University Press.

Huang, G. (2006). The determinants of capital structure: Evidence from China. China Economic Review, 17(1), 14-36.

Huang, S. G., \& Song, F. M. (2004). The determinants of capital structure: Evidence from China. China Economic Quarterly-Beijing- 3, 395-414

Jensen, M. C., \& Meckling, W. H. (1976). Theory of the firm: Managerial behavior, agency costs and ownership structure. Journal of Financial Economics, 3(4), 305-360.

Kara, E., \& Erdur, D. A. (2015). Determinants of capital structure: A research on sectors that contribute to exports in Turkey. Istanbul University Journal of the School of Business, 44(2), 027-038.

Kaur, R., \& Rao, N. K. (2009). Determinants of capital structure: Experience of Indian cotton textile industry. Vilakshan: The XIMB Journal of Management, 6(2).

Kula, V. (2000). Küçük ve orta ölçekli imalat işletmelerinin sermaye yapısını etkileyen faktörler ve Afyon'daki işletmeler üzerine bir araştırma. Afyon Kocatepe Üniversitesi Sosyal Bilimler Enstitüsü, Doktora Tezi, Afyon.

Mallikarjunappa, T., \& Goveas, C. (2007). Factors determining the capital structure of pharmaceutical companies in India. The ICFAI Journal of Applied Finance, 13(11), 56-72.

Manos, R., \& Ah-Hen, C. (2003). Evidence on the determinants of capital structure of non-financial corporates in Mauritius. Journal of African business, 4(2), 129-154

Miller, M. H. (1977). Debt and taxes. the Journal of Finance, 32(2), 261-275.

Modigliani, F., \& Miller, M. H. (1958). The cost of capital, corporation finance and the theory of investment. The American Economic Review, 48(3), 261-297.

Modigliani, F., \& Miller, M. H. (1963) Corporate income taxes and the cost of capital: A correction. The American Economic Review, 53, 433-443.

Myers, S. C. (1977). Determinants of corporate borrowing. Journal of financial economics, 5(2), 147-175.

Myers, S. C. (1984). The capital structure puzzle'. Journel of Finance, 39(3), 574-592.

Özer, B., \& Yamak, S. (2000). Self-sustaining pattern of finance in small businesses: Evidence from Turkey. International Journal of Hospitality Management, 19(3), 261-273.

Özkan, A. (2001). Determinants of capital structure and adjustment to long run target: Evidence from UK company panel data. Journal of Business Finance \& Accounting, 28(1-2), 175-198.

Pandey, I. M. (2001). Capital structure and the firm characterstics: Evidence from an emerging market. IIMA Working Paper No. 2001-10-04.

Pazarlığlu, M. V., \& Gürler, Ö. K. (2007). Telekomünikasyon yatırımları ve ekonomik büyüme: Panel veri yaklaşımı. Finans Politik ve Ekonomik Yorumlar, 44(508), 35-43. 
Pozdena, R. J. (1987). Tax policy and corporate capital structure. Economic Review-Federal Reserve Bank of San Francisco, (4), 37.

Sayılgan, G., Karabacak, H., \& Küçükkocaoğlu, G. (2006). The firm-specific determinants of corporate capital structure: Evidence from Turkish panel data. Investment Management and Financial Innovations, 3(3), 125-139.

Sayılgan, G., Uysal, B., \& Enstitüsü, S. B. (2011). Türkiye Cumhuriyet Merkez Bankası sektörel bilançoları kullanılarak sermaye yapısını belirleyen faktörler üzerine bir analiz: 1996-2008. Ankara Üniversitesi SBF Dergisi, 66(04), 101124.

Shah, A., \& Khan, S. (2007). Determinants of capital structure: Evidence from Pakistani panel data. International Review of Business Research, 3(4), 265-282.

Shah, S. Z. A. Jam-e-Kausar (2012). Determinants of capital structure of leasing companies in Pakistan. Applied Financial Economics, 22(22), 1841-1853.

Şen, M., \& Oruc, E. (2008). Testing of pecking order theory in ISE (Istanbul Stock Exchange Market). International Research Journal of Finance and Economics, 21, 19-26.

Taggart, R. A. (1980). Taxes and corporate capital structure in an incomplete market. The Journal of Finance, 35(3), 645659.

Teker, D., Tasseven, O., \& Tukel, A. (2009). Determinants of capital structure for Turkish firms: A panel data analysis. International Research Journal of Finance and Economics, 29, 179-187.

Terim, B., \& Kayalı, C. A. (2009). Sermaye yapısını belirleyici etmenler: Türkiye'de imalat sanayi örneği. Celal Bayar Üniversitesi Sosyal Bilimler Dergisi, 7(1), 125-154.

Thippayana, P. (2014). Determinants of capital structure in Thailand. Procedia-Social and Behavioral Sciences, 143, 10741077.

Titman, S., \& Wessels, R. (1988). The determinants of capital structure choice. The Journal of Finance, 43(1), 1-19.

Tortop, M. (2007), Çokuluslu Isletmelerde Sermaye Yapısı Ve iMKB'de Bir Uygulama. Master Thesis. Gazi Üniversitesi Sosyal Bilimler Enstitüsü, Ankara.

Titman, S., \& Wessels, R. (1988). The determinants of capital structure choice. The Journal of Finance, 43(1), 1-19

Upneja, A., \& Dalbor, M. (2001). The choice of long-term debt in the US lodging industry. Journal of Hospitality, Tourism, Leisure Science, 1(1), 1-19.

Uysal, B. (2010), Sermaye yapısını belirleyen faktörler: Sektörel bir inceleme. Yüksek Lisans Tezi, Ankara.

Vergas, N., Cerqueira, A., \& Brandão, E. (2015). The determinants of the capital structure of listed on stock market nonfinancial firms: Evidence for Portugal (No. 555). Universidade do Porto, Faculdade de Economia do Porto.

Voulgaris, F., Asteriou, D., \& Agiomirgianakis, G. (2004). Size and determinants of capital structure in the Greek manufacturing sector. International Review of Applied Economics, 18(2), 247-262.

Wiwattanakantang, Y. (1999). An empirical study on the determinants of the capital structure of Thai firms. Pacific-Basin Finance Journal, 7(3), 371-403.

Wooldridge, J. M. (2002). Econometric analysis of cross section and panel data. The MIT Press.

Yakar, R. (2011). Sermaye yapısı teorileri ve iMKB'de ampirik bir uygulama. Selçuk Üniversitesi Sosyal Bilimler Enstitüsü, Doktora Tezi, Konya.

Yıldırım, D., \& Eyceyurt, T. (2012). Sermaye yapısını etkileyen faktörler: gıda sektöründe bir uygulama. 16. Finans Sempozyumu Bildiriler Kitabı, 363- 378.

Yildiz, M. E., Yalama, A., \& Sevil, G. (2009). Sermaye yapısı teorilerinin geçerliliğinin test edilmesi: Panel veri analizi kullanılarak iMKB-imalat sektörü üzerinde ampirik bir uygulama. Iktisat Isletme ve Finans, 24(278), 25-45.

Yilgör, A. G., \& Yücel, E. (2007). Sermaye yapısı kararlarına ilişkin Mersin ve Adana illerinde bir uygulama. Muhasebe ve Finansman Dergisi, (35), 1-15. 